\title{
Leader-Member Exchange (LMX) and Psychosocial Factors at Work Among Healthcare Professionals
}

Johansson Hanse, Jan; Harlin, Ulrika; Jarebrant, Caroline; Ulin, Kerstin ; Winkel, Jørgen

Published in:

Journal of Nursing \& Care

Link to article, DOI:

$10.4172 / 2167-1168.1000193$

Publication date:

2014

Document Version

Publisher's PDF, also known as Version of record

Link back to DTU Orbit

Citation (APA):

Johansson Hanse, J., Harlin, U., Jarebrant, C., Ulin, K., \& Winkel, J. (2014). Leader-Member Exchange (LMX) and Psychosocial Factors at Work Among Healthcare Professionals. Journal of Nursing \& Care, 3(5), [1000193]. https://doi.org/10.4172/2167-1168.1000193

\section{General rights}

Copyright and moral rights for the publications made accessible in the public portal are retained by the authors and/or other copyright owners and it is a condition of accessing publications that users recognise and abide by the legal requirements associated with these rights.

- Users may download and print one copy of any publication from the public portal for the purpose of private study or research.

- You may not further distribute the material or use it for any profit-making activity or commercial gain

- You may freely distribute the URL identifying the publication in the public portal 


\title{
Leader-Member Exchange (LMX) and Psychosocial Factors at Work Among Healthcare Professionals
}

Jan Johansson Hanse ${ }^{1,2^{\star}}$, Ulrika Harlin ${ }^{3}$, Caroline Jarebrant ${ }^{3,4}$, Kerstin Ulin $^{5,6}$ and Jörgen Winkel ${ }^{7,8}$

${ }^{1}$ Professor, Nordic School of Public Health NHV, Sweden

${ }^{2}$ Professor, Department of Psychology, University of Gothenburg, Sweden

3 Industrial researcher, Swerea IVF, Mölndal, Sweden

${ }^{4} \mathrm{PhD}$ student, Department of Sociology and Work Science, University of Gothenburg, Sweden

${ }^{5}$ Senior lecturer, PhD, Institute of Health and Care Science, Sahlgrenska Academy, University of Gothenburg, Sweden

${ }^{6}$ Senior lecturer/nurse, Sahlgrenska University Hospital, Gothenburg, Sweden

${ }^{7}$ Senior professor, Department of Management Engineering, Technical University of Denmark, Denmark

${ }^{8}$ Senior professor, Department of Sociology and Work Science, University of Gothenburg, Sweden

*Corresponding author: Professor Jan Johansson Hanse, Nordic School of Public Health, Box 12133, SE-40242 Gothenburg, Sweden, Tel: +46 (0)31 693956 , E-mail: jan.johansson.hanse@nhv.se

Received date: June 07, 2014, Accepted date: August 25, 2014, Published date: August 28, 2014

Copyright: $\odot 2014$ Hanse JJ, et al. This is an open-access article distributed under the terms of the Creative Commons Attribution License, which permits unrestricted use, distribution, and reproduction in any medium, provided the original author and source are credited.

\begin{abstract}
Aim: The study aims to examine the associations between leader-member exchange (LMX) and psychosocial factors at work.

Methods: A questionnaire-based cross-sectional study was undertaken at four units in two not-for-profit hospitals in southwestern Sweden. The study sample included 240 employees.

Results: Significant correlations were found between LMX items and most of the psychosocial domains and dimensions. The strongest correlations were found between the LMX item affect and rewards/recognition, role clarity and predictability, and the LMX item loyalty and rewards/recognition. In sum, high-quality LMX was associated with good psychosocial work conditions experienced by the employees.
\end{abstract}

Conclusions: The results support possible ways for managers and employees to strengthen their relationships and this may in turn lead to more sustainable systems in health care.

Keywords : COPSOQ; Leadership; LMX; Psychosocial

\section{Introduction}

European Agency for Safety and Health at Work [1] has emphasized managerial significance and role in improving the psychosocial work environment among workers. In this study, leadership is based on leader-member exchange quality (LMX). Leader-member exchange quality (LMX) is about the quality of the dyadic, work relationship between an employee and her/his leader (supervisor) in terms of the interrelated dimensions of trust, respect and mutual obligation [2]. LMX theory argues that when the supervisor provides resources in a way that is perceived to be beneficial and fair, the employee will view the relationship positively and reciprocate via increased commitment and effort-resulting in a high quality relationship. It suggests that leaders relationships with subordinates can range from those based solely on the formal employment contract (low quality LMX) to those that are characterized by mutual trust, respect and reciprocal influence (high quality LMX) [3]. Previous studies indicate that LMX relationships establish rather quickly and stabilize [4]. Past research has demonstrated that LMX is correlated to a number of important outcomes for employees. The quality of LMX has been found to be associated with job satisfaction, positive work attitudes, wellbeing, organizational commitment and performance [5-8]. Previous studies also have shown that adverse psychosocial workplace factors can increase the risk of ill-health (e.g. musculoskeletal disorders, stressrelated disorders, burnout, sickness absence, labor turnover) among workers in general $[9,10]$ and among healthcare workers [11]. Healthcare workers report high levels of workplace stress and are at a higher risk of mental health problems than many other occupational groups [12]. Therefore the present study aims to examine the associations between leader-member exchange (LMX) and psychosocial factors at work among healthcare professionals. The study reports findings from the Swedish part of a Nordic Multicenter Study regarding performance and wellbeing in Lean rationalization processes at hospitals [13].

\section{Methods}

\section{Procedure and participants}

A questionnaire-based cross-sectional study was undertaken at four units in two not-for-profit hospitals in southwestern Sweden. The study was based on questionnaires carried out at the hospital units during working time. The subjects answered the questionnaire 
anonymously. Oral and written information was given regarding the confidentiality of the survey process, noting that all results would only be reported back to the organization in aggregate for the unit as a whole. The study sample included 240 employees.

\section{Measures}

\section{Demographic and employee-related variables}

This part consisted of items concerning sex, age (6-point response scale; younger than 20 years, 20-29 years, 30-39 years, 40-49 years, 50-59 years, 60 years or older), years of employment at the hospital unit (4-point response scale; less than 3 months, 3-12 months, 1-3 years, more than 3 years) and job title/profession (5-point response scale; registered nurse, enrolled nurse, secretary, physician, another position).

\section{Leader-member exchange (LMX)}

The quality of the supervisor-employee ('follower') relationship was measured according to the Leader - member exchange (LMX) theory [14]. In the current study, employee-rated LMX was measured using four items from Liden and Maslyn's LMX-scale [15]: affect, loyalty, contribution and professional respect. These four items represent four sub-dimensions to measure the employees' perception of the quality of relationship with their supervisors. In the current study we used a short version of the employee-rated LMX [15] with one item for each dimension:

- - 'Affect': My supervisor is a lot of fun to work with.

- - 'Loyalty': My supervisor would defend me to others in the organization if I made an honest mistake.

- 'Contribution': I am willing to apply extra efforts, beyond those normally required, to meet my supervisor's work goals.

- - 'Professional respect': I respect my supervisor's knowledge of and competence on the job.

Each item was rated using a seven-point Likert-type scale where higher scores represent higher quality exchanges, i.e. high-quality LMX ( 1 = strongly disagree to 7 = strongly agree). In the current study, Cronbach alpha reliability for the LMX global scale was .87 .

\section{Psychosocial factors at work}

The psychosocial work environment was measured with scales from the Copenhagen psychosocial questionnaire (COPSOQ) [16]. The COPSOQ has been used in more than 10 years as a tool for assessing the psychosocial work environment [9] and is a suitable instrument to measure the psychosocial work environment among hospital workers [11]. Reliabilities estimates with Cronbach's alpha, Green's test-retest alpha and intraclass coefficient (ICC) are according standard guidelines adequate to good [17].

The following domains and dimensions (scales) were used [16], where high scores represent good psychosocial work conditions:

Domain: 'Demands at work', with the following dimensions:

- 'Quantitative demands' (4 items, each item had five fixed response alternatives): Is your workload unevenly distributed so it piles up? How often do you not have time to complete all your work tasks? Do you get behind with your work? Do you have enough time for your work tasks?
- 'Tempo/Work pace' (3 items, each item had five fixed response alternatives): Do you have to work very fast? Do you work at a high pace throughout the day? Is it necessary to keep working at a high pace?

Domain: 'Work organization and job contents', with the following dimension:

- 'Influence at work' (4 items, each item had five fixed response alternatives): Do you have a large degree of influence concerning your work? Do you have a say in choosing who you work with? Can you influence the amount of work assigned to you? Do you have any influence on what you do at work?

Domain: 'Interpersonal relations', with the following dimensions:

- 'Predictability' (2 items, each item had five fixed response alternatives): At your place of work, are you informed well in advance concerning for example important decisions, changes, or plans for the future? Do you receive all the information you need in order to do your work well?

- 'Rewards/Recognition' (2 items from the short version, each item had five fixed response alternatives): Is your work recognized and appreciated by the management? Are you treated fairly at your workplace?

- 'Role clarity' (3 items, each item had five fixed response alternatives): Does your work have clear objectives? Do you know exactly which areas is your responsibility? Do you know exactly what is expected of you at work?

Domain: 'Values at workplace level', with the following dimensions:

- 'Trust regarding management' ('vertical trust') (2 items, each item had five fixed response alternatives): Does the management trust the employees to do their work well? Can you trust the information that comes from the management?

- 'Justice and Respect' (2 items, each item had five fixed response alternatives): Are conflicts resolved in a fair way? Is the work distributed fairly?

- The COPSOQ item 'Job satisfaction' was also included in the current study: Regarding your work in general. How pleased are you with your job as a whole, everything taken into consideration? (four fixed response alternatives).

\section{Data analyses}

Descriptive statistics and reliabilities (Cronbach's alpha) were calculated. The data were analyzed using Pearson correlation and hierarchical linear regression analysis to assess the association between LMX items and psychosocial factors at work. In the hierarchical linear regression analysis the variables were entered in two (or more) steps in the following order: demographic variables (method enter), LMX variables (method stepwise).

The level of significance was set at $\mathrm{p}<.05$. The size of the effect was determined according to conventions by Cohen [18]. Cohen defined effect sizes for correlations of around 0.10 as 'small', around 0.30 as 'medium' and around 0.50 as 'large'. In multiple regression analysis (R-square) the effect classes are around 0.02 for 'small', around 0.13 for 'medium' and around 0.26 for 'large'.

SPSS version 21.0 for Windows was utilized to perform the statistical analyses. 
Page 3 of 5

\section{Results}

\section{Demographic and employee-related variables among healthcare professionals}

The sample $(\mathrm{n}=240)$ consisted of 59 per cent registered nurses, 24 per cent enrolled nurses, 10 percent secretaries and 6 per cent physicians. Of the respondents, 82 per cent were females and 18 per cent were males. Twenty-three per cent were younger than 30 years, 62 per cent were between $30-49$ years and 15 per cent were 50 years or older. As regards the period of employment at the hospital unit, 23 per cent had less than one year employment, 17 per cent between one and three years and 60 per cent had more than three years of employment.

\section{Bivariate associations between LMX and psychosocial factors at work}

Significant correlations were found between LMX items and most of the psychosocial domains and dimensions. High-quality LMX was associated with good psychosocial work conditions experienced by the employees.

The strongest correlations were found between LMX and the domains interpersonal relations ( $\mathrm{r}$ between 0.31-0.51, $\mathrm{p}<0.001$ ) and values at workplace level ( $\mathrm{r}$ between $0.31-0.42, \mathrm{p}<0.001)$. At dimension level, the strongest correlations were found between the LMX item affect and rewards/recognition $(\mathrm{r}=0.51, \mathrm{p}<0.001)$, role clarity $(\mathrm{r}=0.47, \quad \mathrm{p}<0.001)$ and predictability $(\mathrm{r}=0.47, \quad \mathrm{p}<0.001)$ respectively, and the LMX item loyalty and rewards/recognition $(\mathrm{r}=0.48, \mathrm{p}<0.001)$.

Somewhat lower correlations were found between LMX and the domains work organization and job contents ( $\mathrm{r}$ between $0.19-0.23$, $\mathrm{p}<0.01$ ) and demands at work ( $\mathrm{r}$ between $0.03-0.29$ ). Within the domain demands at work there were no significant correlations between LMX items and the dimension tempo/work pace ( $\mathrm{r}$ between $0.03-0.08, \mathrm{~ns})$.

The findings also reveal that the quality of the LMX has significant relationships with job satisfaction ( $r$ between $0.29-0.45, p<0.001$ ). The strongest correlations was found between the LMX item affect and job satisfaction $(\mathrm{r}=0.45, \mathrm{p}<0.001)$. The higher quality of LMX, the higher job satisfaction was experienced by the staffs.

\section{Multiple associations between LMX and psychosocial factors at work}

Next, we examined the relationship between LMX items and psychosocial domains, after controlling for demographic variables in step 1 (Tables 1-5).

As shown in Table 1 in the hierarchical regression analyses, we found that one (professional respect) of the four LMX items in the models was significantly associated with demands at work $(\beta=0.19$, $\mathrm{p}<0.01)$. The LMX items affect, loyalty and contribution were not significantly associated with this psychosocial domain, when entered with other variables (demographics and LMX).

\begin{tabular}{|l|l|l|l|l|l|l|}
\hline & \multicolumn{3}{|l|}{ Model 1 } & \multicolumn{4}{l|}{$\begin{array}{l}\text { Model 2 or 3 (last } \\
\text { model) }\end{array}$} \\
\hline Variable & $\mathrm{B}$ & $\mathrm{SE}(\mathrm{B})$ & $\beta$ & $\mathrm{B}$ & $\mathrm{SE}(\mathrm{B})$ & $\beta$ \\
\hline Age & 0.04 & 0.04 & 0.08 & 0.04 & 0.59 & 0.08 \\
\hline
\end{tabular}

\begin{tabular}{|c|c|c|c|c|c|c|}
\hline Sex & 0.11 & 0.09 & 0.09 & 0.09 & 0.28 & 0.08 \\
\hline Years of employment & -0.01 & 0.04 & -0.02 & 0.00 & 0.07 & 0.13 \\
\hline Professional respect ${ }^{a}$ & & & & 0.07 & 0.02 & $0.19^{* *}$ \\
\hline Adjusted $\mathbf{R}^{2}$ & \multirow{2}{*}{\multicolumn{3}{|c|}{$\begin{array}{l}0.01 \\
0.67\end{array}$}} & \multirow{2}{*}{\multicolumn{3}{|c|}{$\begin{array}{l}0.03 \\
7.20^{* *}\end{array}$}} \\
\hline$F$ for change in $R^{2}$ & & & & & & \\
\hline
\end{tabular}

Table 1: Hierarchical multiple regression analysis for LMX items (independent variables) on Demands at work (dependent variable). Demographic variables were entered in step $1(n=240)$.

Note: $\quad{ }^{*} \mathrm{p}<0.05 ;{ }^{* *} \mathrm{p}<0.01 ;{ }^{* * *} \mathrm{p}<0.001$

$\mathrm{a}=$ Model 2

$\mathrm{b}=$ Model 3

Examination of the data in Table 2 show that one (contribution) of the four LMX items in the models was significantly associated with the domain work organization and job contents $(\beta=0.22, \mathrm{p}<0.01)$. The LMX items affect, loyalty and professional respect were not significantly associated with this psychosocial domain, when entered with other variables (demographics and LMX).

\begin{tabular}{|c|c|c|c|c|c|c|}
\hline & \multicolumn{3}{|c|}{ Model 1} & \multicolumn{3}{|c|}{ Model 2 or 3 (last model) } \\
\hline Variable & B & $\mathrm{SE}(\mathrm{B})$ & $\beta$ & B & $S E(B)$ & $\beta$ \\
\hline Age & 0.04 & 0.05 & 0.07 & 0.05 & 0.05 & 0.08 \\
\hline Sex & -0.14 & 0.12 & -0.09 & -0.14 & 0.11 & -0.09 \\
\hline Years of employment & -0.04 & 0.05 & -0.06 & -0.06 & 0.05 & -0.10 \\
\hline Contribution $^{a}$ & & & & 0.10 & 0.03 & $0.22^{* *}$ \\
\hline Adjusted $\mathbf{R}^{2}$ & \multirow{2}{*}{\multicolumn{3}{|c|}{$\begin{array}{l}0.00 \\
1.07\end{array}$}} & \multirow{2}{*}{\multicolumn{3}{|c|}{$\begin{array}{l}0.04 \\
9.53^{* *}\end{array}$}} \\
\hline$F$ for change in $R^{2}$ & & & & & & \\
\hline
\end{tabular}

Table 2: Hierarchical multiple regression analysis for LMX items (independent variables) on Work organization and job contents (dependent variable). Demographic variables were entered in step 1 $(\mathrm{n}=240)$

$$
\begin{aligned}
& \text { Note: }{ }^{*} \mathrm{p}<0.05 ;{ }^{* *} \mathrm{p}<0.01 ;{ }^{* *} \mathrm{p}<0.001 \\
& \mathrm{a}=\text { Model } 2 \\
& \mathrm{~b}=\text { Model } 3
\end{aligned}
$$

Table 3 shows that that two (affect \& professional respect) of the four LMX items in the models was significantly associated with the domain interpersonal relations $(\beta=0.40, p<0.001 \& \beta=0.28, p<0.001)$. The LMX items loyalty and contribution were not significantly associated with this psychosocial domain, when entered with other variables (demographics and LMX).

\begin{tabular}{|l|l|l|l|l|l|l|}
\hline & \multicolumn{2}{|l|}{ Model 1 } & \multicolumn{3}{l|}{ Model 2 or 3 (last model) } \\
\hline Variable & B & SE(B) & $\beta$ & $B$ & $S E(B)$ & $\beta$ \\
\hline Age & -0.04 & 0.04 & -0.07 & -0.05 & 0.03 & -0.11 \\
\hline Sex & -0.15 & 0.10 & -0.11 & -0.15 & 0.08 & -0.11 \\
\hline
\end{tabular}


Page 4 of 5

\begin{tabular}{|c|c|c|c|c|c|c|}
\hline Years of employment & -0.01 & 0.04 & -0.01 & -0.02 & 0.03 & -0.04 \\
\hline Affect ${ }^{b}$ & & & & 0.15 & 0.03 & $0.40^{4 * t *}$ \\
\hline Professional respect ${ }^{b}$ & & & & 0.11 & 0.03 & $0.28^{* * * t}$ \\
\hline Adjusted $\mathbf{R}^{2}$ & \multirow{2}{*}{\multicolumn{3}{|c|}{$\begin{array}{l}0.00 \\
0.95\end{array}$}} & \multirow{2}{*}{\multicolumn{3}{|c|}{$\begin{array}{l}0.36^{\mathrm{a}} / 0.40^{\mathrm{b}} \\
115.22^{\mathrm{a}^{*+* *}} / 13.76^{\mathrm{b}^{*+*}}\end{array}$}} \\
\hline$F$ for change in $R^{2}$ & & & & & & \\
\hline
\end{tabular}

Table 3: Hierarchical multiple regression analysis for LMX items (independent variables) on Interpersonal relations (dependent variable). Demographic variables were entered in step $1(n=240)$.

$$
\begin{aligned}
& \text { Note: }{ }^{*} \mathrm{p}<0.05 ;{ }^{* *} \mathrm{p}<0.01 ;{ }^{* * *} \mathrm{p}<0.001 \\
& \mathrm{a}=\text { Model } 2 \\
& \mathrm{~b}=\text { Model } 3
\end{aligned}
$$

As can be seen in Table 4 two (loyalty \& professional respect) of the four LMX items in the models was significantly associated with values at workplace level $(\beta=0.30, \mathrm{p}<0.001 \& \beta=0.21, \mathrm{p}<0.01)$. The LMX items affect and contribution were not significantly associated with this

\begin{tabular}{|c|c|c|c|c|c|c|}
\hline \multirow[b]{2}{*}{ Variable } & \multicolumn{3}{|c|}{ Model 1} & \multicolumn{3}{|c|}{ Model 2 or 3 (last model) } \\
\hline & B & $S E(B)$ & $\beta$ & B & $\mathrm{SE}(\mathrm{B})$ & $\beta$ \\
\hline Age & -0.04 & 0.05 & -0.06 & -0.05 & 0.04 & -0.08 \\
\hline Sex & 0.01 & 0.11 & 0.00 & 0.02 & 0.10 & 0.01 \\
\hline Years of employment & 0.00 & 0.05 & 0.00 & -0.02 & 0.04 & -0.03 \\
\hline Loyalty ${ }^{b}$ & & & & 0.13 & 0.03 & $0.30^{* * *}$ \\
\hline Professional respect ${ }^{b}$ & & & & 0.09 & 0.04 & $0.21^{*}$ \\
\hline Adjusted $\mathbf{R}^{2}$ & \multirow{2}{*}{\multicolumn{3}{|c|}{$\begin{array}{l}0.00 \\
0.23\end{array}$}} & \multirow{2}{*}{\multicolumn{3}{|c|}{$\begin{array}{l}0.17 a / 0.20 b \\
46.12 a^{* *} / 6.24 b^{*}\end{array}$}} \\
\hline$F$ for change in $R^{2}$ & & & & & & \\
\hline
\end{tabular}
psychosocial domain, when entered with other variables (demographics and LMX).

Table 4: Hierarchical multiple regression analysis for LMX items (independent variables) on Values at workplace level (dependent variable). Demographic variables were entered in step $1(\mathrm{n}=240)$.

$$
\text { Note: }{ }^{*} \mathrm{p}<0.05 ;{ }^{* *} \mathrm{p}<0.01 ;{ }^{* *} \mathrm{p}<0.001
$$

$\mathrm{a}=$ Model 2

$\mathrm{b}=$ Model 3

Examination of the data in Table 5 demonstrate that one (affect) of the four LMX items in the models was significantly associated with job satisfaction $(\beta=0.43, \mathrm{p}<0.001)$. The LMX items contribution, loyalty and professional respect were not significantly associated with this

\begin{tabular}{|c|c|c|c|c|c|c|}
\hline Years of employment & -0.02 & 0.04 & -0.04 & -0.02 & 0.04 & -0.05 \\
\hline Affect ${ }^{a}$ & & & & 0.16 & 0.02 & $0.43^{* * * x}$ \\
\hline Adjusted $\mathrm{R}^{2}$ & \multirow{2}{*}{\multicolumn{3}{|c|}{$\begin{array}{l}0.00 \\
0.20\end{array}$}} & \multirow{2}{*}{\multicolumn{3}{|c|}{$\begin{array}{l}0.17 \\
45.18^{* * *}\end{array}$}} \\
\hline$F$ for change in $R^{2}$ & & & & & & \\
\hline
\end{tabular}
psychosocial domain, when entered with other variables (demographics and LMX).

\begin{tabular}{|l|l|l|l|l|l|l|}
\hline & \multicolumn{2}{|l|}{ Model 1 } & \multicolumn{3}{l|}{ Model 2 or 3 (last model) } \\
\hline Variable & B & SE(B) & $\beta$ & $B$ & SE(B) & $\beta$ \\
\hline Age & 0.03 & 0.04 & 0.06 & 0.01 & 0.04 & 0.02 \\
\hline Sex & 0.04 & 0.10 & 0.03 & 0.03 & 0.09 & 0.02 \\
\hline
\end{tabular}

Table 5: Hierarchical multiple regression analysis for LMX items (independent variables) on Job satisfaction (dependent variable). Demographic variables were entered in step $1(n=240)$.

$$
\begin{aligned}
& \text { Note: }{ }^{*} \mathrm{p}<0.05 ;{ }^{* *} \mathrm{p}<0.01 ;{ }^{* *} \mathrm{p}<0.001 \\
& \mathrm{a}=\text { Model } 2 \\
& \mathrm{~b}=\text { Model } 3
\end{aligned}
$$

\section{Discussion}

LMX is multi-dimensional measure [15]. This measure assesses a global score for the exchange as well as for the four sub-dimensions of affect, loyalty, contribution and professional respect. Affect measures the employees liking for the supervisor, loyalty measures the degree of loyalty the respondent feels from the supervisor, contribution measures the amount of the respondents own effort exhibited in achieving work goals, and professional respect measures the respondents professional esteem for the supervisor. The most striking result to emerge from the data is that at least one (sometimes several) LMX-item(s) was significantly associated with almost all psychosocial factors at work. The only non-significant association was found between LMX-items and the dimension tempo/work pace.

In previous studies LMX has been found to be significantly associated with psychosocial factors at work (e.g. job satisfaction, work attitudes, wellbeing, organizational commitment) [5-8]. The results from the current study are consistent with those of other studies and suggest that LMX and psychosocial factors are related also among healthcare professionals. The strongest correlations were found between LMX and the domains interpersonal relations ( $\mathrm{r}$ between 0.31 $-0.51, \mathrm{p}<0.001$ ) and values at workplace level ( $\mathrm{r}$ between $0.31-0.42$, $\mathrm{p}<0.001$ ). These effect sizes are 'medium' to 'large' according to Cohen [18]. LMX focuses on the unique relationships that may develop between supervisors and individual employees within an organization. Each sub-dimension of LMX emphasizes a unique aspect of leaderemployee (follower) relationship. Each aspect has the potential to help increase our understanding of which aspects that are significantly associated with various psychosocial factors at work. It seem reasonable to conclude that a good relationship with the supervisor (high LMX) relates to the meaningfulness of work, as staffs could get more interesting work and more understanding of their role within the hospital organization. By improving psychosocial factors at work, it is possible to promote employee health as well as to prevent employee illheath [19].

Another important finding was that the higher quality of LMX, the higher job satisfaction was experienced by the staffs. The effect sizes of these associations are 'medium' to 'large' according to Cohen [18]. The strongest association was found between the LMX-item affect and job satisfaction. The LMX-item affect measures the employees liking for the supervisor. This association was expected as job satisfaction is an affective response (the emotional response to a situation) based upon the degree to which a job fulfills various factors, both intrinsic and extrinsic, that are valued by the individual employee. In previous 
studies job satisfaction has been found to be is an important factor influencing the health of workers [20]. Achieving a high level of job satisfaction among healthcare professionals is an important objective since it may positively impact organizational efficacy, make the staff motivated and feel that they are a part of the organization [1,21].

\section{Limitations and Future Research}

Although our study contributes to social exchange relationships and its associations with psychosocial factors at work among healthcare professionals, several limitations must be recognized. The data were cross-sectional. The cross-sectional nature of the data calls into question any inferences one makes concerning the directionality of relationships, which implies the relationships observed cannot be interpreted causally. Therefore, we recommend longitudinal research. Another potential limitation of the study is same-source dataincreasing concern for common method variance problem. However, by using multiple measures (questions) of each domain/dimension tends to reduce the effect of measurement error [22]. Moreover, this study is limited in its applicability to other employment settings. The findings may not be consistent with studies conducted within industries. It is recommended that research in the future employs diverse sample so that the generalizability of findings to other settings can be enhanced.

In the current study, as well as in previous studies LMX have mostly been measured by taking only the employee (follower) perspective. This may be a weakness, but previous studies shows that LMX agreement (i.e. the extent to which leader and employee ratings of LMX are intercorrelated) are rather low [6]. It seems that employee and leader perspectives measure different aspects of the relationship. In the current study, focus was upon employees' perspective as regards social exchange relationships.

\section{Conflict of Interest}

The authors declare no potential conflicts of interest with respect to the research and/or publication of this article.

\section{Acknowledgements}

Financial support for this research was provided by AFA Insurance and Region Västra Götaland in Sweden. The authors would like to thank the participating health care professionals and our collaborators at the hospital units.

\section{References}

1. European Agency for Safety and Health at Work (2013) Healthy workplaces. Manage stress. campaign guide. Managing stress and psychosocial risks at work.

2. Graen GB, Uhl-Bien M (1995) Relationship-based approach to leadership: Development of leader - member exchange (LMX) theory of leadership over 25 years: Applying a multilevel multi-domain perspective. Lead Quart 6: 219-247.
3. Liden RC, Graen G (1980) Generalizability of the vertical dyad linkage model of leadership. Acad Manag J 23: 451-465.

4. Liden RC, Wayne SJ, Stilwell D (1993) A longitudinal study on the early development of leader-member exchanges. J Appl Psych 78: 662-674.

5. Cropanzano R, Mitchell MS (2005) Social exchange theory: An interdisciplinary review. J Manag 31: 874-900.

6. Gerstner CR, Day DV (1997) Meta-analytic review of leader-member exchange theory: Correlates and construct issues. J Appl Psych 82: 827844 .

7. Randall ML, Cropanzano R, Bormann CA, Birjulin A (1999) Organizational politics and organizational support as predictors of work attitudes, job performance, and organizational citizenship behavior. J Org Behav 20: 159-174.

8. Schyns B, Paul T, Mohr G, Blank H (2005) Comparing antecedents and consequences of LMX in German working context to findings in the US. Europ J Work Org Psych 14: 1-22.

9. Kristensen TS, Hannerz H, Høgh A, Borg V (2005) The Copenhagen Psychosocial Questionnaire--a tool for the assessment and improvement of the psychosocial work environment. Scand J Work Environ Health 31: 438-449.

10. Nieuwenhuijsen K, Bruinvels D, Frings-Dresen M (2010) Psychosocial work environment and stress-related disorders, a systematic review. Occup Med (Lond) 60: 277-286.

11. Aust B, Rugulies R, Skakon J, Scherzer T, Jensen C (2007) Psychosocial work environment of hospital workers: validation of a comprehensive assessment scale. Int J Nurs Stud 44: 814-825.

12. Peterson U, Demerouti E, Bergström G, Samuelsson M, Asberg M, et al. (2008) Burnout and physical and mental health among Swedish healthcare workers. J Adv Nurs 62: 84-95.

13. Winkel J, Birgisdóttir BD, Dudas K, Edwards K, Gunnarsdóttir S, et al. (2012) A Nordic work environment complement to value stream mapping (VSM) for sustainable patient flows at hospitals - A NOVO multicenter study. Proceedings of the 6th NOVO Symposium: Sustainable Health Care: Continuous Improvement of Processes and Systems. Karolinska Institute, Stockholm Sweden. November 15-16, pp 57-58. ISBN: 978-91-637-2380-3.

14. Graen GB, Scandura TA (1987) Toward a psychology of dyadic organization. Res Org Behav 9: 175 - 208.

15. Liden RC, Maslyn JM (1998) Multidimensionality of leader-member exchange: An empirical assessment through scale development. J Manag 24: 43-72.

16. Pejtersen JH, Kristensen TS, Borg V, Bjorner JB (2010) The second version of the Copenhagen Psychosocial Questionnaire. Scand J Public Health 38: 8-24.

17. Thorsen SV, Bjorner JB (2010) Reliability of the Copenhagen psychosocial questionnaire. Scand J Pub Health 38 (Suppl. 3): 25-32.

18. Cohen J (1988) Statistical power analysis for the behavioral sciences. 2nd ed. Hillsdale, NJ: Lawrence Earlbaum Associates.

19. Lohela M, Björklund C, Vingård E, Hagberg J, Jensen I (2009) Does a change in psychosocial work factors lead to a change in employee health? J Occup Environ Med 51: 195-203.

20. Faragher EB, Cass M, Cooper CL (2005) The relationship between job satisfaction and health: a meta-analysis. Occup Environ Med 62: 105-112.

21. Bhatnagar K, Srivastava K (2012) Job satisfaction in health-care organizations. Ind Psychiatry J 21: 75-78.

22. Kline RB (1998) Principles and practice of structural equation modelling. The Guilford Press, New York. 